\title{
Electronic Ginseng 2.0
}

\author{
Victoria Bradbury \\ University of North Carolina Asheville \\ 1 University Heights, Asheville, NC 28804 \\ vbradbur@unca.edu
}

\begin{abstract}
Electronic Ginseng 2.0 is an interactive artwork that allows visitors to animate a screen-based abstraction of a ginseng trade model while causing the roots of a sculpture to jolt and the stem and leaves to grow.
\end{abstract}

Digital fabrication, interactive sculpture, physical computing.

\section{INTRODUCTION}

Electronic Ginseng 2.0 is an interactive kinetic sculpture in the shape of a ginseng plant with digitally fabricated leaves, stems, roots and gears. The sculpture remains still until a visitor interacts with a screen-based interface, inducing an animated abstraction of a ginseng trade model. As this interaction occurs, the plant's sculptural roots begin to move and the leaves, stem and berries emerge and grow.

\section{MOTIVATION AND CONCEPTUAL BACKGROUND}

In Electronic Ginseng 2.0, Arduino and servo motors mediate the interaction between visitor, computer interface and the sculpture. This 2017 project follows the artist's 2012 Electronic Ginseng, created when she was living in China and working out of Xinchejian Hackerspace in Shanghai. Now based in the Appalachian region in Western North Carolina, the artist has begun to re-visit this body of work.

"Wild ginseng challenges an east toward west production and trade model. In Chinese medicine, American Ginseng has a calming effect to balance its Yang cousin, Asian ginseng. American ginseng is highly sought after in China and a complex cultivation and trade industry has grown around the demand. The ginseng plant grows wild in Appalachia and has served as sole or supplemental income for generations of Appalachian families. The wild plant can be elusive and is thought to evade discovery and harvest. This project concerns ginseng's tricky biological, mythological, and economic lore." (Bradbury, 2012)

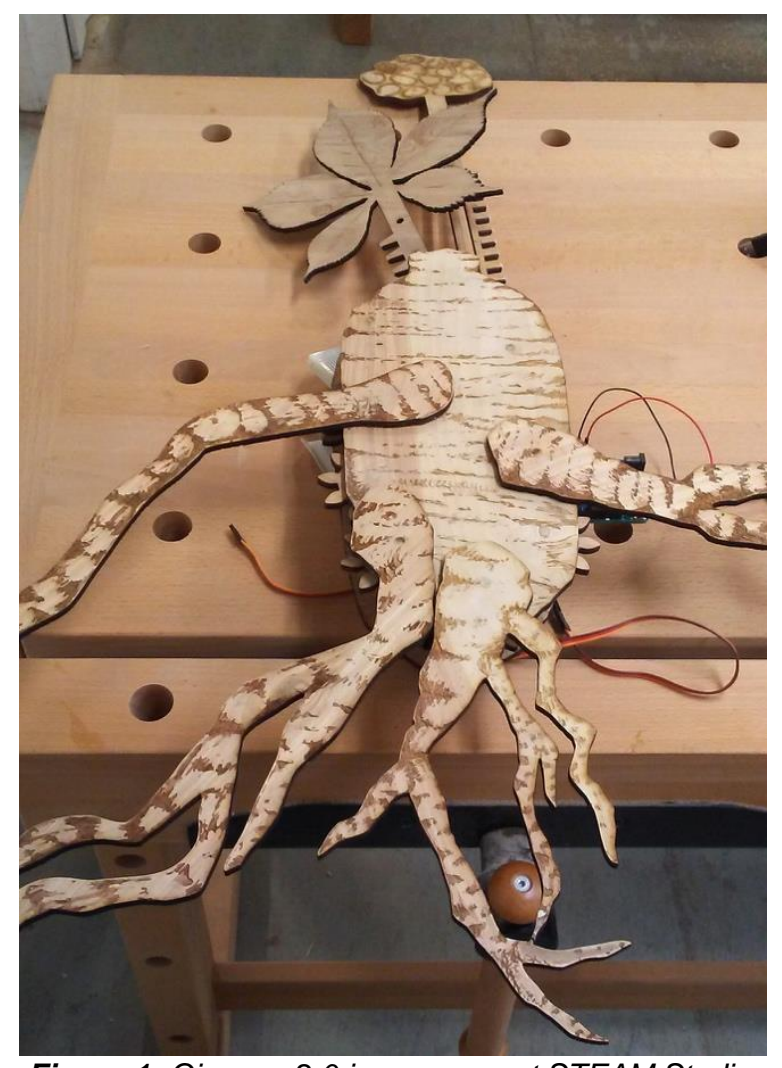

Figure 1: Ginseng 2.0 in-progress at STEAM Studios, River Arts Maker Place, UNC Asheville. Bradbury, 2017.

\section{ARTIST BIO}

Victoria Bradbury is a new media artist weaving programming code, physical computing, body and object. She completed her PhD "The Performativity of Code in Participatory New Media Artworks" with CRUMB at the University of Sunderland in 2015 and is currently Assistant Professor of New Media at 
University of North Carolina Asheville. While residing in the UK from 2013-2015, she was artistin-residence at Digital Media Labs (Barrow-inFurness, 2014), a member of the British Council team for Hack the Space, Tate Modern (London, 2014) and a lead artist for Thinking Digital Arts // Hack (Newcastle, 2014).

www.blurringartandlife.com

\section{REFERENCES}

Bradbury, V. (2012) Electronic Ginseng. http://blurringartandlife.com/vb/ginseng.html (June 16, 2017).

\section{A. TECHNICAL DESCRIPTION OF THE PIECE:}

Title of Work: Electronic Ginseng 2.0

Dimensions (at largest size): 31" x 34"

This sculpture will hand on a wall, preferably far enough away so that visitors can look behind to see the mechanism.

Interactive interface: The sculpture requires a computer and a screen-based interface on which a visitor will click buttons to causes an animation of ginseng to move across the screen while also causing the sculpture to move.

The above will require a computer, screen and mouse, to be supplied by $\mathrm{BHCl} 2017$ Interactions Gallery.

As a second alternative, the ginseng can move with a button press or a proximity sensor. This will not require a computer

Link to images of the project (still in-progress): https://drive.google.com/drive/folders/0B0fjk GLm 9W-bGViYURCdk9HU28?usp=sharing 